\title{
Discussões em torno do referendo sobre o comércio de armas de fogo e munição na Folha de S. Paulo
}

Lauriston de Araújo Carvalho

Daniel Henrique Pereira Espíndula

\section{Introdução}

A onda de temor diante de situações ameaçadoras tem gerado problemas e discussões nas esferas social, econômica e política, diante da incapacidade da sociedade em responder adequadamente a questões relativas à violência. Segundo Glassner (2003), a disparidade entre a magnitude do fenômeno e sua baixa resolutividade contribui para que a violência se configure como um problema de difícil prevenção ou controle.

As temáticas da violência em geral e da criminalidade em específico têm merecido crescente atenção de pesquisadores nos últimos anos. Para Ramos e Novo (2003), o entendimento do universo complexo das determinações dos diversos fenômenos abrangidos pelo rótulo da violência tem sido um desafio para as ciências sociais nas últimas décadas.

O discurso do medo e da insegurança está presente na vida dos moradores em vários espaços sociais, e não apenas nos grandes centros urbanos, ecoando também em regiões mais afastadas das capitais e nas zonas rurais. Um levantamento realizado por Waiselfisz (2015) apontou para um aumento de 387\% no número de mortes por armas de fogo no Brasil entre 1980 e 2012. Em dados absolutos, nesse período 880.386 pessoas morreram por disparo de arma de fogo no país, e, desse total, 747.760 foram assassinadas. Os dados para 2012 (42.416 óbitos) mostram ainda que os jovens na faixa de 15 a 29 anos foram as maiores vítimas (24.882 ou 59\% dos casos), representando uma taxa de mortalidade de 47,6 jovens para cada 100 mil habitantes.

Levando-se em consideração as regiões do Brasil, durante o período de 2002 a 2012, quase todas apresentaram aumento nos índices de mortalidade por causas externas vinculadas a armas de fogo: Norte $(+135,7 \%)$, Nordeste $(+89,1 \%)$, Sul $(+34,6 \%)$ e Centro-Oeste $(+44,9 \%)$. Apenas a região Sudeste apresentou uma queda de $39,8 \%$, protagonizada pelos estados de São Paulo $(-58,6 \%)$ e Rio de Janeiro $(-50,3 \%)$. Ainda segundo Waiselfisz (2015), em 2012 Alagoas configurou-se como o estado com maior taxa de mortos por armas de fogo (55 óbitos para cada 100 mil habitantes), enquanto Roraima foi o estado com a menor taxa: 7,5 para cada 100 mil. 
Em 2012, apesar de as capitais apresentarem índices de morte por armas de fogo maiores que outros espaços urbanos, nas grandes capitais esses índices vêm diminuindo, e aumentando nas demais cidades, o que demonstra o deslocamento da violência para outros espaços geográficos nos estados.

Waiselfisz (2015) mostra que grandes capitais como São Paulo, Rio de Janeiro ou Recife, que na virada de século XX apresentavam elevadas taxas de violência, conseguiram reduzir esses índices, e outras capitais menores, relativamente tranquilas, sofreram grande aumento nesses índices, como João Pessoa, Fortaleza ou Natal.

Nesse cenário destacam-se ainda as mortes ocasionadas em intervenções policiais com armas de fogo, como consequência de políticas de segurança pública, incluindo a chamada "guerra" às drogas. Em relatório da Anistia Internacional (2015), no estado do Rio de Janeiro, num período de dez anos (2005-2014), foram registrados 8.466 casos de homicídio decorrentes de intervenção policial. Especificamente na cidade do Rio de Janeiro, no ano de 2014, os homicídios cometidos por policiais corresponderam a $15,6 \%$ do número total de homicídios. Porém, de todas as 220 investigações envolvendo esses homicídios, apenas um caso teve denúncia apresentada à Corregedoria. Até abril de 2015, 183 investigações seguiam em aberto (Anistia Internacional, 2015).

Mas os danos causados pelo uso de armas de fogo não se restringem aos homicídios. É elevado o número de internações em virtude de lesões por arma de fogo. Aqui há que se considerar também o uso acidental da arma. De cada três internações relacionadas a lesões por arma de fogo no Brasil, uma foi por acidente. Questiona-se se a bala perdida está incluída nessa categoria - o que leva à discussão sobre a necessidade de classificar essa situação em categoria à parte (Phebo, 2005, p. 31).

Dentro desse contexto, há 20 anos, em 1995, o tema do desarmamento, como política de segurança pública, foi pautado, como uma forma de buscar soluções para os altos índices de violência no país, sobretudo as mortes por armas de fogo. Em 1997, o porte de armas de fogo, que antes era considerado apenas contravenção penal, passou a ser crime. Também nesse ano, ampliou-se o rigor para compra e porte desse tipo de arma. Mesmo com essas iniciativas, Dreyfus e Nascimento (2005) mostram que, na década de 2000, o Brasil contava com um arsenal de 15,3 milhões de armas de fogo em mãos privadas, das quais 6,8 milhões registradas junto aos órgãos competentes e 8,5 milhões não registradas, dentre estas, 3,8 milhões estavam em poder de criminosos.

Em 2003, a política nacional de desarmamento foi ampliada com a promulgação da Lei 10.823/03, conhecida como Estatuto do Desarmamento, a qual previa regras ainda mais rígidas para a posse e o porte de armas de fogo e munições no Brasil. A política de controle de armas resultante da aprovação desse Estatuto apresentou resultados favoráveis, conforme aponta Waiselfisz (2015). A avaliação do autor é de que no primeiro ano de vigência da política de controle de armas (2003) houve uma redução de $7,2 \%$ dos homicídios e queda de $8,2 \%$ no número de óbitos registrados em 2003 . Em 
uma análise do período entre 2004 e 2012, estima-se que 160.036 vidas foram poupadas, e, desse total, 113.071 foram de jovens, de acordo com a projeção. Destacase em seu artigo 35 a utilização do instrumento de consulta popular sobre o tema. 0 plebiscito realizado em 2005 instigou 95.375.824 cidadãos a irem às urnas para se posicionar sobre a comercialização de armas de fogo e munição.

Um dos argumentos propagados para a não comercialização de armas de fogo e munição era que ela traria maior segurança para a sociedade, com a diminuição dos crimes passionais e mortes acidentais envolvendo esse tipo de arma. No entanto, o raciocínio inverso também seria utilizado, saber que as pessoas poderiam portar uma arma diminuiria o risco de assaltos. Essa discussão provocou muita polêmica em diversos segmentos sociais e o "não" à proibição da comercialização foi vitorioso.

Invariavelmente, o debate sobre o controle das armas de fogo no Brasil é noticiado pela mídia como política pública sempre que episódios trágicos de violência ganham comoção nacional. O último deles ocorreu em 2011, no estado do Rio de Janeiro, conhecido como o massacre da escola em Realengo, no qual um jovem portando dois revólveres matou 12 crianças e deixou outras 13 feridas. Naquele momento em que a sociedade estava mergulhada em comoção, um decreto legislativo vislumbrava um novo referendo para o mesmo ano, visando a uma reconsulta à população sobre a comercialização das armas de fogo e munição.

Biroli e Mantovani (2010) salientam que os meios de comunicação de massa e a política se inter-relacionam, de modo que a relação estabelecida entre esses dois campos de saberes e práticas constitui o elemento central para o entendimento das disputas eleitorais. Para as autoras, os meios de comunicação se destacam na delimitação do debate público, sobretudo, de duas formas: I- a partir da definição das temáticas que serão consideradas relevantes; e II- consolidando e conferindo sentidos às disputas políticas, estabelecendo diferenciações a partir de clivagens e oposições entre os atores que participam dos debates.

Vários estudos utilizaram fontes jornalísticas para a análise de material de cunho político. Biroli e Mantovani (2014) pesquisaram a cobertura dada pelo jornal Folha de S. Paulo ao processo do Mensalão. Já Mundim (2010) fez uso de um instrumento de testagem para avaliar o efeito da cobertura da imprensa durante as eleições de 2002 e 2006 em quatro grandes jornais brasileiros. Campos (2009) analisou como os crimes de grande repercussão pública de 2003 e 2007 mobilizaram as Propostas de Emendas Constitucionais (PECs) a respeito da maioridade penal a partir de matérias veiculadas na revista Veja e no jornal Folha de S. Paulo. Fonseca (2003) estudou os posicionamentos adotados em quatro jornais de grande circulação nacional sobre a Constituinte entre 1987 e 1988.

Embora pouco presente nas pesquisas na área das ciências humanas, alguns estudos sobre o referendo (Sorj, 2006; Araújo Júnior et al., 2007; Mendonça e Santos, 2009) apresentam a análise dos discursos veiculados nas campanhas televisivas pelos 
grupos do "Sim" e do "Não". Esses trabalhos discutem a lógica argumentativa empregada nas campanhas e o seu papel na construção de um sentido comum à realidade dos grupos sociais, constituindo um valioso material para o entendimento do modo como a sociedade compreendeu esse fenômeno social.

A despeito do processo de compreensão da realidade, Lima e Werneck (2012) entendem o jornalismo como parte de um processo de construção social da realidade e não um espelho dela. Embasados em outros teóricos, os autores ponderam que as "notícias não espelham a realidade. Ao contrário, elas a constituem como um fenômeno social compartilhado, visto que, no processo de descrever o evento, as notícias o definem e redefinem" (Lima e Werneck, 2012, p. 225). Em complemento, Thompson (1995) considera que os meios de comunicação de massa constituem aparatos técnicos de mediação simbólica, capazes de transformar a natureza das interações sociais e as percepções que indivíduos e grupos têm de si mesmos e dos outros. Segundo o autor, os julgamentos e valores que organizam a experiência da realidade podem ser confirmados, (re)produzidos e transformados pela mídia.

Serra e Santos (2003) defendem que o poder atual da mídia estaria na construção, na projeção e na legitimação de significados, dando visibilidade aos fenômenos que atraem primeiramente a atenção dos jornalistas. Ainda segundo os autores, a função destes não se esgota no fato acontecido e no público.

Camargo e Barbará (2004) salientam a importância dos processos de comunicação como um instrumento para a informação e a prevenção ao discutirem o risco da epidemia da Aids. Entendemos que tais processos de comunicação também podem ser aplicados a outros problemas sociais, como os aqui em questão.

Tendo em vista esse papel de mediação e difusão de opinião dos meios de comunicação, este artigo apresenta as discussões em torno do referendo sobre a comercialização de armas de fogo no jornal Folha de S. Paulo no ano 2005 e analisa como tal veículo midiático se preocupou em difundir o tema ao longo dos meses, buscando identificar internamente quais grupos/movimentos sociais tiveram voz na imprensa e puderam expressar suas ideias/opiniões.

\section{Método}

A metodologia utilizada é a pesquisa documental com reportagens de jornal e se insere numa perspectiva descritiva. Utilizando como referência o jornal Folha de S. Paulo, foram coletadas todas as reportagens, dentro do conjunto de cadernos, contendo notícias do referendo sobre o comércio de armas de fogo e munição durante o período de $1^{\circ}$ de janeiro de 2005 a 31 de dezembro de 2005, num total de 170 reportagens. O período dessa coleta justifica-se pelo fato de 2005 ter sido o ano de idealização e realização do referendo, ocorrido em 23 de outubro de 2005. Optou-se pela Folha de S. Paulo por ser o segundo jornal de maior circulação do Brasil, com uma tiragem média de mais de 360 mil 
exemplares e consumido por uma grande variedade de público, sendo suas matérias e reportagens publicadas em diversos jornais por todo o território brasileiro.

O procedimento de busca das reportagens foi realizado pela internet no próprio site do jornal. No campo de busca pelas edições, foram utilizados o descritores: referendo; arma de fogo; munição. O material encontrado foi classificado segundo as variáveis de interesse do estudo, a saber: número de entrada no banco, mês de publicação e caderno de publicação. Foram coletadas as reportagens impressas e online, e para efeito de categorização e classificação as reportagens noticiadas nessas duas formas de veiculação foram consideradas apenas na sua primeira aparição.

\section{Processo de tratamento e análise de dados}

O processo de análise de dados caminhou por duas frentes, segundo os objetivos do estudo. O primeiro processo de tratamento e análise atentou para a frequência com que o tema foi noticiado ao longo dos meses durante o período pesquisado. Todas as reportagens encontradas foram tabuladas quanto ao mês, e logo depois foi contabilizada a frequência simples ao longo dos 12 meses de 2005.

O segundo procedimento de tratamento e análise dos dados buscou compreender o modo como o jornal apresenta a discussão em torno da temática do referendo de armas de fogo a partir da Classificação Hierárquica Descendente realizada pelo software Alceste - Analyse de Lexèmes Concurrent dans les Ennoncés Simples d'un Texte (Reinert, 1990). Após o processo de tabulação, todo o material encontrado foi processado pelo software.

A respeito desse software, Menandro (2004) o apresenta ao mesmo tempo como uma técnica e uma metodologia, o qual visa à apreensão de informações essenciais contidas em um conjunto de textos conexos e volumosos. Sua aplicação é eficaz em dados provenientes de diversos procedimentos de coleta que tenham em comum a linguagem verbal (entrevistas, grupos focais, artigos de imprensa, obras literárias etc.). Já Fonseca (2010) destaca que a organização dos dados pelo Alceste é viabilizada por meio de análises estatísticas e matemáticas, as quais fornecem o número de classes, as relações estabelecidas entre elas, as formas radicais e palavras associadas com seus respectivos valores de qui-quadrado.

Uma das análises básicas do Alceste é a Análise de Classe ou contexto lexical ${ }^{1}$. São os temas extraídos da análise do corpus. Cada classe gerada pelo Alceste corresponde a UCEs específicas identificadas por meio do vocabulário contido nelas. A força de relação com que cada UCE e/ou palavra se relaciona a uma classe é determinada pelo valor do qui-quadrado $\left(X^{2}\right)($ Cortez, 2006).

\footnotetext{
${ }^{1}$ Outra análise básica do software é a Unidade de Contexto Elementar (UCE) (Cortez, 2006). A UCE corresponde à frase dimensionada em função do comprimento e da pontuação. É a partir dela que o software realiza o trabalho de classificação (Oliveira, Gomes e Marques, 2005).
} 
A Classificação Hierárquica Descendente, utilizada aqui, consiste em um tipo de análise realizada pelo Alceste, a qual, segundo Cortez (2006), elabora uma classificação definitiva do vocabulário específico para cada classe, levando em consideração alguns elementos, a saber: frequência, percentagem e coeficiente de relação da palavra com o texto no qual está inserida. Ao final do processo de classificação, o software organiza os dados das classes sob a forma de representação gráfica de uma árvore - dendrograma -, que indica o número de classes, suas estruturas e a forma de relação entre elas, proximidade e/ou oposição Cortez (2006).

\section{Resultados}

A análise da Classificação Hierárquica Descendente (CHD) realizada pelo Alceste indicou que a discussão do referendo sobre o comércio de armas de fogo pela Folha de $S$. Paulo no ano de 2005 distribuiu-se em seis classes distintas organizadas em torno de dois grandes grupos, conforme pode ser observado na Figura 1:

Figura 1

Dendrograma referendo sobre comércio de armas de fogo na Folha de S. Paulo

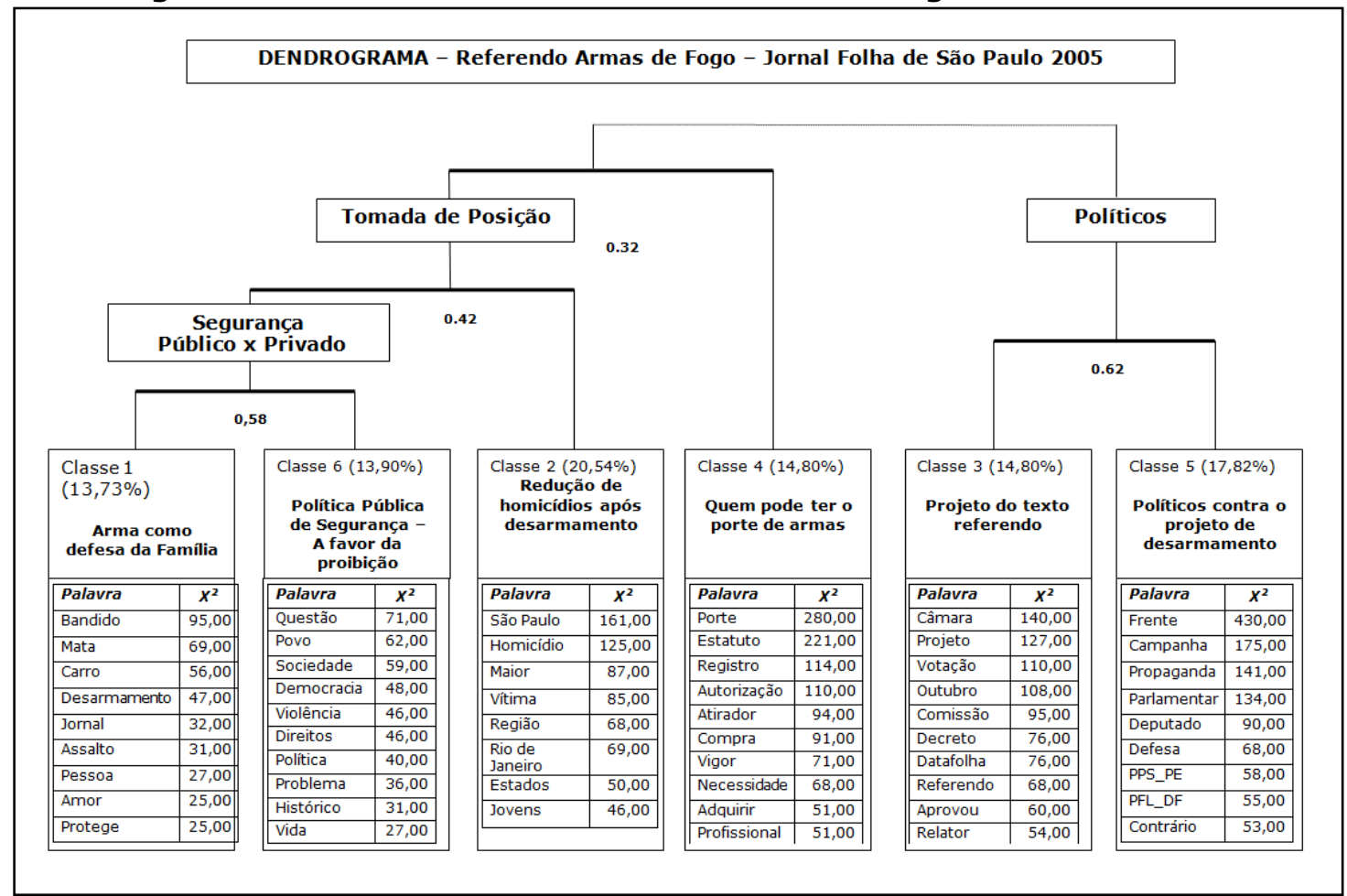

Fonte: A figura foi gerada pela análise do software Alceste. A análise foi baseada nos dados coletados no jornal Folha de S. Paulo, durante o ano de 2005.

Os valores isolados $0.58,0.42,0.32$ e 0.62 significam força de correlação entre classes, subeixos e eixos. Quanto mais próximo de 1,00 mais forte é a proximidade (força de correlação) entre as classes. 
A classificação hierárquica descendente preservou $70,16 \%$ de todo o material processado. Conforme o dendrograma da Figura 1, o primeiro grande grupo estruturado, Tomada de Posição, é formado por: classe 1 - Arma como defesa da família; classe 6 Política pública de segurança - A favor da proibição; classe 2 - Redução dos homicídios após desarmamento; e classe 4 - Quem pode ter o porte de armas. O segundo grande grupo, Políticos, é formado por: classe 3 - Projeto do texto referendo; e classe 5 Políticos contra o projeto de desarmamento.

As classes 1, 6 e 2, quando agrupadas internamente em torno do primeiro eixo, apresentam em sua composição a discussão do referendo a partir das posições positiva e negativa em relação à temática, via apresentação de relatos e discursos de diversos atores favoráveis e contrários ao porte de armas de fogo no país. Ainda compondo o primeiro eixo, temos a classe 4, em que o jornal informa aos leitores quem pode ter o porte de armas a partir do projeto de lei.

A classe 1 refere-se à arma de fogo como instrumento de defesa familiar. As ideias que fundamentam essa classe mostram o desejo do cidadão comum em proteger a si próprio e a sua família, apoiando-se no direito legal de legítima defesa assegurado pela Constituição federal. A fim de facilitar o entendimento das classes apresentadas pelo Alceste, serão apresentados trechos das reportagens coletadas que mais expressam as ideias contidas nas classes. O programa é capaz ainda de destacar as palavras mais representativas dentro do texto a partir da análise lexical do qui-quadrado de cada termo, aqui apresentadas em negrito:

João concordou, mas notou que ele não bebe nunca, não usa droga e está bem de cabeça, tudo verdade. Uma arma em casa lhe daria uma certa segurança, a impressão de poder defender sua família. (Folha de $S$. Paulo, 6 de outubro de 2005 - Ilustrada).

Arma de fogo é um objeto inanimado, não sai por aí matando pessoas. Quem mata é o criminoso, é o ser humano com valores deturpados, pois qualquer objeto pode ser usado para matar: pedras, paus, facas, carro, motos, drogas (Folha de S. Paulo, 9 de julho de 2005 - Cotidiano).

Uma questão importante, que pode ser elencada a partir da ideia apresentada na classe 1, da arma como instrumento de defesa da família, é que os discursos veiculados pela Folha de S. Paulo, via depoimentos, relatos de experiências e crenças pessoais, enfocam apenas os atributos positivos relacionados à posse de arma dentro de casa. As experiências negativas não foram elencadas. A possibilidade de aumento de riscos de acidentes domésticos e a probabilidade de eventos seguidos de morte de moradores e/ou pessoas próximas ao domicílio parecem não ter sido objeto de interesse e reflexão. Mantendo relação com a classe 1 , que defende a segurança a partir de movimentos de ordem privada, encontramos na classe 6 a defesa de que a segurança dos cidadãos deve 
ser realizada pelos órgãos públicos, a partir de políticas públicas de segurança. Tal proposta é apresentada na perspectiva preventiva de projeto do governo e da sociedade para o combate à violência. Essa classe possui uma relação de antagonismo com a classe anterior, ao propor o desarmamento da família como medida possível a ser encorajada com a proibição da comercialização de armas de fogo e munição.

O mais importante no debate sobre o desarmamento é a mobilização contra a violência, e insistir na educação para a cidadania, na valorização e respeito da vida, na promoção da justiça social e na construção da cultura da paz. (Folha de S. Paulo, 24 de setembro de 2005 - Opinião).

Os discursos apresentados estão centrados no tema da violência como um problema de âmbito social, devendo-se construir para isso agendas públicas para prevenção da violência, a partir de políticas sociais de educação e direitos humanos, por exemplo. Além de defender o desarmamento dos atores sociais, as ideias presentes na classe 6, mencionadas pelo jornal Folha de S. Paulo, apontam para o mote da oposição armamento/desarmamento no interior da discussão da violência social. O desarmamento seria então mais uma política pública preventiva contra o agravo social.

Já a classe 2 - Redução dos homicídios após desarmamento - tem como enfoque apresentar ao leitor os indicadores positivos via redução do número de mortes por causas externas pelas armas de fogo, conforme pode ser verificado nas reportagens:

De acordo com o estudo, nos estados onde houve alta taxa de recolhimento de armas, mais de 150 a cada 100 mil habitantes, o índice de mortalidade apresentou recuo médio de 14,5\% (Folha de S. Paulo, 3 de setembro de 2005 - Cotidiano).

Os dados mostraram que, em um só ano, 3.234 vidas foram poupadas. São números incontestáveis, já que o Ministério da Saúde cruzou dados do sistema de informações sobre mortalidade com o número de armas recolhidas e revelou que as maiores quedas ocorreram justamente nos estados que mais recolheram armas (Folha de S. Paulo, 9 de outubro de 2005 - Opinião).

A classe 4 - Quem pode ter o porte de armas - apresenta o debate envolvendo o Estatuto do Desarmamento, dando ênfase aos sujeitos e grupos sociais que podem ter a posse de armas de fogo. Essa classe mostra temporalmente a elaboração do projeto, pontuando os pré-requisitos necessários para a obtenção do porte de armas, como a necessidade de comprovar atividade profissional de risco:

O porte é conferido apenas a pessoas com efetiva necessidade por exercício de atividade profissional de risco. A propriedade de uma arma pelo atirador não deve ser confundida com o porte de arma, que 
será conferido apenas a pessoas que demonstrem efetiva necessidade por exercício de atividade profissional de risco e o caso de seguranças, juízes e promotores (Folha de S. Paulo, 17 de outubro de 2005 Cotidiano).

A descrição apresentada aos leitores a respeito da lei em tramitação na época sobre o porte de armas era que a posse de armas não seria aberta a todo e qualquer cidadão, mas àqueles que exercessem atividades de risco. A reportagem procurou apresentar ainda a diferença entre porte de armas por conta de atividades de risco e o porte de armas para um atirador desportista.

O segundo agrupamento de ideias, representado pelas classes 3 - Projeto do texto do referendo - e 5 - Políticos contra o projeto de desarmamento -, apresenta em comum discursos em torno do debate e da agenda política do referendo sobre o comércio de armas de fogo. Os políticos mais atuantes também foram elencados durante o processo de análise. A classe 3, em especial, apresenta aos leitores o processo de construção do projeto de lei do referendo elaborado pelos parlamentares, causando grande polêmica, com ênfase na pergunta a ser respondida no referendo.

A Câmara dos Deputados deve aprovar em breve o projeto de decreto legislativo que define a pergunta a ser feita no referendo nacional sobre armas. Se não houver alterações, os eleitores brasileiros serão convocados em algum domingo de outubro próximo a responder à pergunta: o comércio de armas de fogo e munição deve ser proibido no Brasil? (Folha de S. Paulo, 15 de maio de 2005 - Opinião).

O jornal analisado apresenta vários políticos envolvidos diretamente no processo, os quais, em diversas ocasiões ao longo dos meses, tomam a frente das campanhas e mobilizam-se para defender seus pontos de vista, como pode ser verificado na classe 5 - Políticos contra o projeto de desarmamento.

Já o deputado Alberto Fraga, PFL-DF, presidente da frente pelo direito à legítima defesa, disse que seu grupo está se preparando para a campanha igualitária de rádio e televisão (Folha on-line, 1 de agosto de 2005 - Cotidiano).

Renan Calheiros (PMDB-AL), presidente do Senado, assume a presidência da frente pela proibição, enquanto a secretaria geral do grupo fica a cargo do deputado Raul Jungmann (PPS-PE) (Folha de S. Paulo, 13 de agosto de 2005 - Política).

Não obstante a formação da classe 5 - Políticos contra o projeto de desarmamento -, a tomada de posição a favor ou contra o desarmamento dividiu os líderes partidários no Poder Legislativo, políticos das duas casas se posicionaram ante o 
referendo, liderando a causa em polos opostos, favoráveis e contrários à proibição do comércio de armas de fogo.

A análise dos grupamentos apresenta ainda outros elementos. Observa-se, por exemplo, no primeiro agrupamento, formado pelas classes 1, 6, 2 e 4, com 62,97\% de todo o material analisado, uma discussão em torno da problemática da segurança pessoal, se se trata de um problema a ser resolvido no âmbito da esfera pública ou no da esfera privada. As ideias se referem à arma de fogo como instrumento de defesa familiar (classe 1), utilizadas pelos adeptos da campanha do "Não", denominados "Pelo Direito da Legítima Defesa". Chama atenção aqui o esforço conduzido pelos parlamentares e pela imprensa em apresentar a temática da defesa da família e da propriedade privada e a construção da imagem de um inimigo externo a elas na figura do bandido, diferente do "cidadão de bem". A classe 6 apresenta uma ligação com esta última por oferecer uma oposição, mostrando o desarmamento e as ações de prevenção da violência como estratégia de política pública de segurança do governo e da sociedade civil.

O mais importante no debate sobre o desarmamento é a mobilização contra a violência, e insistir na educação para a cidadania, na valorização e respeito da vida, na promoção da justiça social e na construção da cultura da paz (Folha de S. Paulo, 24 de setembro de 2005, Opinião).

Essa oposição soma-se à classe 2, que exibe uma série de dados estatísticos que mostram a redução do número de homicídios após o Estatuto do Desarmamento, principalmente em relação aos acidentes domésticos.

O desarmamento teve impacto na baixa dos homicídios. Nos estados em que a taxa de recolhimento de armas foi alta (mais de 150 para cada 100 mil habitantes), o recuo médio do índice de mortalidade foi de 14,5\% (Folha de S. Paulo, 9 de outubro de 2005 - Opinião).

O Ministério da Saúde informa que os homicídios por armas de fogo caíram 8,2\% em 2004 em relação a 2003. Foram de 39.325 assassinatos em 2003 para 36.091 no ano seguinte (Folha de S. Paulo, 12 de outubro de 2005 - Opinião).

O segundo eixo, denominado Políticos, agrupando as classes 3 e 5, apresenta os trâmites para elaboração do projeto do referendo, como também as primeiras movimentações de parlamentares que resultaram na formação dos grupos que se posicionaram em relação ao referendo.

A Comissão de Constituição e Justiça (CCJ) da Câmara dos Deputados aprovou ontem o projeto que marca para 2 de outubro o referendo sobre o fim da comercialização de armas de fogo no país. Segundo o deputado João Paulo Cunha (PT-SP), relator na CCJ, o TSE 
poderá mudar a data para 30 de outubro. A lei atribui ao órgão a definição do dia da consulta (Folha de S. Paulo, 12 de maio de 2005).

Finda a apresentação dos resultados e elencadas as principais ideias apresentadas pelo jornal Folha de S. Paulo quanto à questão do referendo sobre o comércio de armas de fogo, segue a discussão dos resultados à luz das teorias comunicacionais que analisam a relação entre a mídia e a agenda política.

\section{Discussão}

A análise das reportagens mostra o modo como a imprensa apresenta o tema do referendo sobre o comércio de armas de fogo e munição, indicando os pontos positivos e negativos sobre a questão. A introdução desses pontos valorativos está diluída principalmente nas classes do primeiro agrupamento de ideias, apresentando reflexões em direção à sensibilização do eleitorado brasileiro.

$\mathrm{Na}$ análise dos dados do primeiro agrupamento de classes, observa-se que as ideias se referem à arma de fogo como instrumento que promoveria a integridade e a segurança familiar (classe 1). O argumento da integridade e, sobretudo, o da legítima defesa constituíram-se em um dos elementos utilizados pelos defensores da campanha do "Não", denominados "Pelo Direito da Legítima Defesa". As ideias chamam atenção pelo esforço em ancorar o porte de armas de fogo na lógica da defesa da família e na construção imagética de um inimigo ameaçador externo a ela. Os discursos encontrados realizam uma distinção entre o grupo que compõe o modelo de um "cidadão de bem", membro da família e responsável pela sua guarda, e os outros, ameaçadores desse ordenamento. Outros estudos também apontam o outro ameaçador e estranho (Lima et al., 2005; Silva, 2010; Zaluar e Barcellos, 2013), que na maioria das vezes é apresentado, nas justificativas de defesa do porte de armas, como assaltante, bandido, estuprador ou outros atores sociais que agem utilizando coerção física para obter proventos, por exemplo, os agiotas e a milícia.

Ao que parece, a imprensa traçou um perfil do "cidadão de bem", que se diferencia do perfil do bandido, para defender o porte de armas: enquanto as pessoas "de bem" utilizariam armas para se defender, estando amparadas por práticas sociais pacatas e condizentes com valores socialmente positivados, como ausência de vícios, os bandidos, por sua vez, não necessitam estar de posse de uma arma de fogo, pois qualquer objeto a sua volta pode tornar-se uma arma letal. O argumento para a defesa da posse de armas por membros da sociedade estaria resguardado em atributos psicológicos inerentes ao sujeito.

É interessante observar que a crença compartilhada entre as classes na personificação desse sujeito violento pode estar relacionada à crença na associação entre juventude e violência (Assis, 1999; Espíndula et al., 2006), caracterizada nas figuras bandido, vítima, morte. Uma análise mais detalhada das reportagens deixa perceptíveis 
as periódicas tentativas de incluir no texto do referendo a redução da maioridade penal, delegando ao jovem a maior responsabilidade pela violência ocorrida com armas de fogo:

O relator do projeto (...) quer incluir em seu parecer a realização da pergunta sobre a redução da maioridade penal para 16 anos (Folha de $S$. Paulo, 18 março de 2005 - Cotidiano).

Há, no Congresso Nacional, numerosos projetos de lei relativos ao rebaixamento da maioridade penal. É preciso consolidá-los numa proposta de emenda constitucional, instituindo mudança importante para coibir a violência (Folha de S. Paulo, 23 dezembro de 2005 - Opinião).

A classe 6 apresenta uma ligação com esta última (classe 5) por oferecer uma oposição, mostrando o desarmamento da família como estratégia de política pública do governo e da sociedade civil. Essa oposição soma-se à classe 2, exibindo uma série de dados estatísticos que mostram a redução do número de homicídios após a vigência do Estatuto do Desarmamento, principalmente em relação aos acidentes domésticos.

Como explicam Bandeira e Bourgeois (2005), o desarmamento da família parece ser uma saída interessante, haja vista ser significativamente alta a porcentagem de homicídios entre familiares, mesmo depois do Estatuto do Desarmamento. Os autores apresentam ainda dados da Confederação Nacional dos Municípios de 2010, em que, considerando a variável de gênero, dos 2.148 homicídios de mulheres em 2009, 21,9\% ocorreram no domicílio da vítima, o que revela que a afirmação que atribui sempre ao bandido a responsabilidade pelos homicídios não corresponde aos fatos e desconsidera as altas taxas de crimes domésticos de várias naturezas, como pedofilia, violência contra o idoso, contra a mulher etc. Outro ponto de destaque diz respeito ao número de vítimas e aos agravos gerados pela violência com o uso de armas de fogo. Sanches, Duarte e Pontes (2009) trazem à tona o número de vítimas fatais e sequelas graves que podem permanecer por toda a vida, sobretudo na população jovem. Martins e Jorge (2013) discutem as mortes por causas externas a partir das diferenças entre seus motivos, apontando que a intencionalidade sobressai em relação aos acidentes, gerando assim muito mais riscos à sociedade. Outras possibilidades de estratégias preventivas que coadunam com o desarmamento das famílias também podem ser encontradas, por exemplo, nos estudos de Andrade (2013) e Bonamigo (2013), que discutem o papel das políticas públicas de segurança na prevenção da violência.

Porém, mais de uma década depois do referendo, as pautas para revogação do Estatuto do Desarmamento e a favor da redução da maioridade penal, paralelamente, começam a avançar na Câmara dos Deputados. Em 19 de agosto de 2015, a PEC 171/93 da redução da maioridade penal foi aprovada pela Câmara dos Deputados em dois turnos, reduzindo a idade penal de 18 para 16 anos para crimes hediondos, homicídios dolosos e lesões com morte. Em primeiro turno, a aprovação se deu com 323 votos favoráveis e 155 contrários. Já em segundo turno, por 320 votos a favor, 152 contra e 1 
abstenção. A partir de agora a matéria segue para o Senado, onde passará novamente por duas votações.

O discurso do medo, de acordo com Glassner (2003), complementa essa discussão. A forma como os eventos violentos são noticiados pela mídia constrói no imaginário social o desestabilizador clima de tensão e pânico sobre a violência com armas de fogo, o que leva à urgência por encontrar os culpados, elegendo-se entre os responsáveis alvos mais vulneráveis, como o jovem.

A classe 3 - Projeto do texto do referendo - apresenta forte ligação com a classe 5, denominada Políticos contra o projeto de desarmamento, formando o segundo agrupamento de ideias. Essas classes referem-se aos trâmites para elaboração do projeto do referendo, como também às primeiras movimentações de parlamentares que resultaram na formação dos grupos que se posicionaram contra e a favor à posse de armas de fogo.

O que fica evidente nessas classes são as sucessivas tentativas de incluir no texto do referendo outras temáticas de grande relevância nacional relativas ao fenômeno da violência com armas de fogo. Dentre esses temas, os principais são a redução da maioridade penal, já citada anteriormente, e a pena de morte, cuja defesa é protagonizada pelo deputado e policial militar coronel Alves (PL-AP):

A entidade (CNBB) também está preocupada com o "lobby das armas", que tem trabalhado junto a deputados federais para mudar a proposta da consulta popular, com a inclusão de perguntas extras, sobre pena de morte (Folha on-line, 3 de março de 2005 - Cotidiano).

O relator do projeto (...) Coronel Alves (PL-AP), pretende incluir a realização de duas perguntas extras na consulta popular. Uma sobre o apoio à pena de morte e outra sobre a redução da maioridade penal para 16 anos (Folha on-line, 27 de abril de 2005 - Editorial).

Esses temas aparecem desde as primeiras especulações sobre o referendo e dividem opiniões entre os parlamentares, impulsionando a formação dos primeiros arranjos dos futuros grupos concorrentes quanto ao referendo. No entanto, Lins, Figueiredo Filho e Silva (2016), a partir de análises estatísticas, testam a hipótese de que a redução da maioridade penal reduziria a violência em vários países do mundo e concluem que, quanto menor o patamar da maioridade penal, maior será a incidência de violência.

Diante da análise das reportagens, de modo geral, podemos inferir que a Folha de S. Paulo se enquadra nas características da difusão (Moscovici, 2012). Segundo o autor, o uso da difusão é marcado pelo direcionamento das notícias a um público diversificado e o conteúdo objetiva se adequar às preferências do seu leitor. As notícias têm estilo sensacionalista, concreto, sedutor e rápido e propõem apenas informar, sem posicionamento determinante perante o fato. $O$ abuso de uma linguagem impactante, as 
histórias de vida marcadas pela violência, os dados estatísticos de homicídios consumados etc., com o objetivo de chocar e sensibilizar o leitor/eleitor, são predominantes nas reportagens. A grande quantidade de informações e uma ampla variedade de temas envolvendo o referendo, sem sinalizar para nenhum dos dois grupos concorrentes, aparentando não ter a intenção de mudar a conduta dos leitores, é também um traço marcante que dá a entender que ojornal usa da difusão.

No entanto, embora a Folha de S. Paulo desempenhe bem a função dos jornais difusores, há de se considerar, além da difusão, também a utilização da propaganda nas suas mensagens. Aléssio, Apostolidis e Santos (2008) explicam que as mensagens na propaganda são persuasivas com o objetivo de influenciar o comportamento do público, demonstrando uma visão dicotômica do mundo, no que é posto como bom e ruim, verdadeiro e falso. A análise se refere a uma grande quantidade de artigos dedicados aos argumentos dos grupos do "sim" e do "não", que permeiam as classes do primeiro agrupamento de ideias.

Esses argumentos de fato têm a intenção de se dirigir a determinados grupos sociais e visam preservar suas ideologias. Araújo Júnior et al. (2007) apresentam detalhadamente essa questão, demonstrando os grupos de interesse no referendo, a ponto de financiarem as campanhas. As empresas do grupo do "Sim", representadas por Ambev e Viva Rio, receberam recursos da Fundação Ford, Fundação Soros, ONU, CBF e Prestadora de Serviços Estruturar, acumulando um total de $R \$ 2,4$ milhões para a campanha. Por parte do grupo do "Não", as empresas domésticas de armas e munições Taurus e CBC foram as grandes financiadoras, doando um total de $\mathrm{R} \$ 5$ milhões. Tais resultados são similares aos encontrados por Azevedo (2001), a respeito da visão difundida de que, dada a natureza comercial ou as ligações políticas com seus proprietários, a imprensa busca defender os interesses dos grupos dominantes.

Os constantes esforços em defesa da família, do homem "de bem", do direito de legítima defesa, por exemplo, podem constituir uma tentativa de garantir a manutenção desses valores e ideologias já cristalizados, com a finalidade de influenciar as atitudes do grupo, nesse caso votar sim ou não. Desse modo, utilizando da propagação nas mensagens, os grupos buscam preservar os seus eleitores e a possibilidade de adquirir outros.

Assim, podemos concluir que o referendo sobre o comércio de armas de fogo, como objeto inédito, estranho, é o elemento desestabilizador a se adequar aos valores do grupo. Tal entendimento é passível de verificação quando se observam as características da propagação, em que aqueles que comunicam procuram aqui controlar as ameaças dos novos conhecimentos sobre os objetos que fazem parte do seu próprio sistema de crenças, interpretando-os à luz desse sistema, que deve ser preservado (Allain, Nascimento-Schulze e Camargo, 2009).

É interessante observar que, nos dois grupos concorrentes, as ideias, os valores, as ideologias de cada grupo se ligam aos seus representantes. O grupo "Pelo Direito de 
Legítima Defesa" teve como principal expoente o então deputado federal Alberto Fraga. O grupo do "Sim", favorável à proibição da comercialização de armas, contava, por sua vez, com a colaboração do então presidente do Senado Renan Calheiros. Os conteúdos e as formas como o jornal construiu as notícias mostram que as ideias de um determinado grupo estão contempladas quando essas figuras públicas são mencionadas, não sendo assim necessário descrever opiniões, posicionamentos sobre o referendo, porque já estão subentendidos.

\section{Conclusão}

Este artigo buscou compreender o modo como o jornal Folha de S. Paulo acompanhou e noticiou a temática do referendo sobre o comércio de armas de fogo meses antes do pleito, em outubro de 2005. O que se verificou foi que esse jornal se preocupou em apresentar a temática a partir de dois lados de forma igualitária, o favorável e o contrário ao desarmamento, bem como os dados da redução da taxa de homicídios após a campanha de desarmamento. Explicações em torno da proposta do desarmamento também se fizeram presentes.

Sendo o Brasil marcado por altos índices de homicídios por armas de fogo, o referendo sobre sua comercialização ganhou notoriedade nacional e as discussões, opiniões e informações sobre ele foram bastante noticiadas pela mídia impressa. Os pontos de vista possibilitam a persuasão do eleitorado, aparecendo em meio a disputas políticas e econômicas, em que há sempre a tentativa de se contrapor ao argumento do grupo oponente.

A discussão envolvendo grupos favoráveis e contrários ao comércio de armas de fogo não foi noticiada apenas a grupos sociais mais específicos, mas também aos mais diversos públicos. O jornal pesquisado mostrou ainda como o grupamento político, via Poder Legislativo, se posicionou em relação à questão do referendo. A partir das análises realizadas das matérias veiculadas que envolviam o referendo sobre a proibição do comércio de armas de fogo, verificamos que a discussão da temática focou a polarização do tema e a tomada de posição dos diversos atores sociais. Em termos de porcentagem do material publicado, verificou-se ainda certo destaque às notícias a favor da proibição das armas de fogo.

Fernandes (2005) complementa essa discussão, mostrando a importância de realizar um debate mais amplo, discutindo as condições de produção e destino das munições. Segundo o autor, 95\% da munição ilegal é produzida em território nacional, o que indica a necessidade de fiscalização mais rigorosa e eficiente pelos órgãos competentes. Como agravante, estima-se que atualmente circulem sem o controle do Estado 16 milhões de armas, $90 \%$ das quais estão em posse da sociedade civil e $48 \%$ delas sem registro. Além do grande número de armas nas mãos de civis, a maior parte da população não tem o treinamento adequado para lidar com uma arma. 
Por fim, gostaríamos de salientar que este artigo, por ser um estudo de pesquisa documental, exploratório e descritivo, apresenta avanços e limitações, o que nos permite chegar a alguns resultados, embora não generalizáveis. A temática do desarmamento não se esgota com o que foi apresentado, mas abre-se mais um caminho para o entendimento e o aprofundamento da questão. Nesse sentido, os novos passos possíveis consistiriam em focar, do ponto de vista midiático, outros tipos de imprensa, como revistas e programas televisivos; explorar outras fontes documentais, tais como registros oficiais; e desenvolver estudos que enfoquem outras fontes, como o levantamento de dados via entrevistas, questionários ou levantamento de opinião. Tais ações ampliariam o debate aqui apresentado.

Lauriston de Araújo Carvalho - Mestre em psicologia, doutorando em psicologia pelo Programa de Pós-Graduação em Psicologia pela Universidade Federal do Rio Grande do Norte - UFRN. E-mail: <lauristonac@hotmail.com>.

Daniel Henrique Pereira Espíndula - Doutor em psicologia, docente do Programa de Pós-Graduação em Psicologia, Universidade Federal do Vale do São Francisco Univasf. E-mail: <daniel.espindula@univasf.edu.br>.

\section{Referências bibliográficas}

Allain, J. M.; NAscimento-Schulze, C. M.; Camargo, B. C. "As representações sociais de transgênicos nos jornais brasileiros". Estudos de Psicologia, vol. 14, n 1, p. 21-30, 2009.

ANDRADE, V. R. P. "A mudança do paradigma repressivo em segurança pública: reflexões criminológicas críticas em torno da proposta da $1^{\circ}$ Conferência Nacional Brasileira de Segurança Pública". Sequência, nº 67, p. 335-356, 2013.

ANISTIA INTERNACIONAL. Você matou meu filho!: homicídios cometidos pela polícia militar na cidade do Rio de Janeiro. Rio de Janeiro: Anistia Internacional, 2015.

ARAújo JúnioR, A. F., et al. "Dê-me segurança ou the dou um não": em busca do eleitor mediano no referendo das armas. Revista Brasileira de Economia, vol. 61, no 4, p. 429-447, 2007.

Assis, S. G. Traçando caminhos numa sociedade menos violenta: a vida de jovens infratores e seus irmãos não infratores. Rio de Janeiro: Fiocruz, 1999.

AZEVEDo, F. A. "Imprensa, cobertura eleitoral e objetividade: a eleição de 2000 na capital paulista". Opinião Pública, vol. 61, n² 2, p. 182-201, 2001.

Bandeira, A. R.; Bourgeois, J. Arma de fogo: proteção ou risco? Rio de Janeiro: Viva Rio, 2005.

BiRoli, F.; MANTOVANI, D. "Disputas, ajustes e acomodações na produção da agenda eleitoral: a cobertura jornalística ao Programa Bolsa Família e as eleições de 2006". Opinião Pública, vol. 16, n 1, p. $90-116,2010$.

. "A parte que me cabe nesse julgamento: a Folha de S. Paulo na cobertura ao processo do Mensalão". Opinião Pública, vol. 20, n² 2, p. 204-218, 2014. 
Bonamigo, I. S. "Novas tecnologias de vigilância e a gestão de violências". Fractal - Revista de Psicologia, vol. 25, n³, p. 659-674, 2013.

BRASIL. Ministério da Saúde. Secretaria de Vigilância em Saúde. Departamento de Análise de Situação em Saúde. Saúde Brasil 2010. Uma análise da situação de saúde e de evidências selecionadas de impacto de ações de vigilância em saúde. Brasília, DF, 2011.

CAMARGo, B. V.; BarbarÁ, A. "Efeitos de panfletos informativos sobre a Aids em Adolescentes". Psicologia: Teoria e Pesquisa, vol. 20, n³, p. 279-287, 2004.

CAMPOS, M. S. "Mídia e política: a construção da agenda nas propostas de redução da maioridade penal na Câmara dos Deputados". Opinião Pública, vol. 15, n² 2, p. 478-509, 2009.

CORTEZ, M. B. "Maridos dominadores, esposas (in)subordinadas: as implicações do empoderamento feminino e da masculinidade hegemônica na violência conjugal". Dissertação de Mestrado. Programa de Pós-Graduação em Psicologia, Universidade Federal do Espírito Santo, Vitória, 2006.

DREYFUS, P.; NASCIMENTO, M. S. Small arms holdings in Brazil: toward a comprehensive mapping of guns and their owners. In: Fernandes, R. (ed.). Brazil: the arms and the victims. Rio de Janeiro: 7 Letras/Viva Rio/Iser, 2005.

EsPínDULA, D. H. P., et al. "'Perigoso e violento': representações sociais de adolescentes em conflito com a lei em material jornalístico". Psic - Revista de Psicologia, vol. 7, n² 2, p. 11-20, 2006.

FERNANDES, R. C. Brasil: as armas e as vítimas. Rio de Janeiro: 7Letras, 2005.

FonseCA, F. "O conservadorismo patronal da grande imprensa brasileira". Opinião Pública, vol. 9, nº 2, p. 73-92, 2003.

FONSECA, L. M. "Termos e expressões utilizados por familiares ao relatarem suas experiências nos diferentes momentos do adoecimento mental". Dissertação de Mestrado apresentada na Escola de Enfermagem de Ribeirão Preto, Universidade de São Paulo - USP, 2010.

GlASSNeR, B. Cultura do medo. Trad. Laura Knapp. São Paulo: Francis, 2003.

LIMA, D.; WeRneCK, V. "A notícia política na mídia evangélica: O Mensageiro da Paz e a Folha Universal em perspectiva comparada". Dados - Revista de Ciências Sociais, vol. 55, n 1, p. 221$250,2012$.

LIMA, M. L. C., et al. "Análise espacial dos determinantes socioeconômicos dos homicídios no estado de Pernambuco". Revista de Saúde Pública, vol. 39, no 2, p. 176-182, 2005.

LiNS, R.; Figueiredo FilHo, D.; Silva, L. "A redução da maioridade penal diminui a violência? Evidências de um estudo comparado". Opinião Pública, vol. 22, n 1, p. 118-139, 2016.

MARTins, C. B. G.; JoRGE, M. H. P. M. "Óbitos por causas externas em Cuiabá, de 0 a 24 anos: perfil das vítimas e famílias segundo a intencionalidade". Revista Brasileira de Epidemiologia, vol. 16, $\mathrm{n}^{\circ}$ 2, p. 454-468, 2013.

MASCARENHAS, M. D. M., et al. Epidemiologia das causas externas no Brasil: mortalidade por acidentes e violências no período de 2000 a 2009. In: Brasil, Ministério da Saúde, Brasil. Saúde Brasil 2010: uma análise da situação de saúde e de evidências selecionadas de impacto de ações de vigilância em saúde, 2010.

MenANDRO, M. C. S. 'Gente jovem reunida: um estudo de representações sociais da adolescência/juventude a partir de textos jornalísticos (1968-1974 e 1996-2002)". Tese de Doutorado. Programa de Pós-Graduação em Psicologia, Universidade Federal do Espírito Santo, Vitória, 2004. 
MENDONÇA, R. F.; SANTOS, D. B. "A cooperação na deliberação pública: um estudo de caso sobre o referendo da proibição da comercialização de armas de fogo no Brasil". Dados, vol. 52, n 2, p. 507$542,2009$.

Moscovici, S. A psicanálise, sua imagem e seu público. Petrópolis: Vozes, 2012.

MUNDIM, P. S. "Um modelo para medir os efeitos da cobertura da imprensa no voto: teste nas eleições de 2002 e 2006". Opinião Pública, vol. 16, n² 2, p. 394-425, 2010.

Oliveira, D. C.; Gomes, A. M. T.; MARques, S. C. Análise estatística de dados textuais na pesquisa das representações sociais: alguns princípios e uma aplicação ao campo da saúde. In: MENIN, M. S. S.; SHImizu, A. M. (orgs.). Experiência e representação social: questões teóricas e metodológicas. São Paulo: Casa do Psicólogo, p. 157-200, 2005.

PHeBo, L. Impacto da arma de fogo na saúde da população no Brasil. In: FERnANDES, R. C. Brasil: as armas e as vítimas. Rio de Janeiro: 7 Letras, p. 9-36, 2005. Disponível em:

<http://comunidadesegura.org.br/files/active/0/vitimas_armas_impacto_saude.pdf >. Acesso em: 27 jul. 2013.

Ramos, F. P.; Novo, H. A. "Mídia, violência e alteridade: um estudo de caso". Estudos de Psicologia, vol. 8, n 3, p. 491-497, 2003.

REINERT, M. "Alceste, une méthodologie d'analyse des données textuelles et une application: Aurelia de Gerard de Nerval". Bulletin de Methodologie Sociologique, vol. 26, p. 24-54, 1990.

SAnChes, S.; DuARTE, S. J. H.; Pontes, E. R. J. C. "Caracterização das vítimas de ferimentos por arma de fogo, atendidas pelo Serviço de Atendimento Móvel de Urgência em Campo GrandeMS". Saúde e Sociedade, vol. 18, nº 1, p. 95-102, 2009.

SerRA, G. M. A.; Santos, E. M. "Saúde e mídia na construção da obesidade e do corpo perfeito". Ciência e Saúde Coletiva, vol. 8, n³, p. 691-701, 2003.

SilVA, L. A. M. "'Violência urbana', segurança pública e favelas: o caso do Rio de Janeiro atual". Caderno $C R H$, vol. 23, n 59, p. 283-300, 2010.

SORJ, B. "Internet, espaço público e marketing político: entre a promoção da comunicação e o solipsismo moralista". Novos estudos - Cebrap, vol. 76, p. 123-136, 2006.

THOMPSON, J. B. Ideologia e cultura moderna: teoria social crítica na era dos meios de comunicação de massa. Petrópolis: Vozes, 1995.

WAISELfiSz, J. J. Homicídios e juventude no Brasil. Brasília, DF, 2013. . O mapa da violência: mortes matadas por armas de fogo. Brasília: Flacso Brasil, 2015.

Zaluar, A.; BARCellos, C. "Mortes prematuras e conflito armado pelo domínio das favelas no Rio de Janeiro". Revista Brasileira de Ciências Sociais, vol. 28, nº 81, p. 17-31, 2013. 


\section{Resumo}

Discussões em torno do referendo sobre o comércio de armas de fogo e munição na Folha de S. Paulo

Este artigo busca compreender os saberes veiculados pelo jornal Folha de S. Paulo a respeito do referendo das armas de fogo durante o ano de 2005. Foram realizadas buscas no site do jornal versão impressa e online via descritores: referendo; arma de fogo; munição, sendo encontradas 170 reportagens. O material foi analisado pelo software Alceste, que realiza análises de dados textuais, via classificação hierárquica descendente. Os resultados indicam a discussão do referendo organizada em dois eixos de significados da ordem da Segurança Privada x Segurança Pública, no qual temas como o controle das armas ilegais e munição são tratados em segundo plano, mostrando a necessidade do aprofundamento da discussão.

Palavras-chave: arma de fogo; munição; imprensa; referendo

\section{Abstract}

Discussions on the firearm and ammunition sales referendum in the newspaper Folha de S. Paulo

This article aims at understanding the facts transmitted by the newspaper Folha de S. Paulo about the firearms and ammunition referendum of 2005. Searches on the newspaper's website were conducted using the following descriptors: referendum; firearm; ammunition. The search resulted in 170 reports, which were analyzed by the Alceste software. The results indicate that the discussion surrounding the referendum was organized into two defined axes of meanings, namely private security and public security, in which themes such as the control of illegal firearms and ammunition are background issues, demonstrating the need to deepen discussions on the topic.

Keywords: firearm; ammunition, press; referendum

\section{Resumen}

Las discusiones sobre el referéndum sobre el comercio de armas de fuego y municiones en el Folha de S. Paulo

Este artículo busca comprender el conocimiento que transmite el diario Folha de S. Paulo sobre el referéndum de armas de fuego durante el año 2005. Se llevaron a cabo búsquedas en la versión impresa de la página del periódico/línea a través de descriptores: referéndum; arma de fuego; municiones. Se encontraron 170 informes, el material se analizó mediante software Alceste, que realiza el análisis de datos de texto a través de la clasificación jerárquica descendente. Los resultados indican la discusión del referéndum organizado en dos ejes de lo que significa el orden de Seguridad Privada contra Seguridad Pública en la que temas como el control de armas y municiones ilegales se manejan en segundo plano, lo que muestra la necesidad de una mayor discusión.

Palabras clave: armas de fuego; municiones; prensa; referéndum

\section{Résumé}

Discussions autour du referendum sur le commerce des armes à feu et les munitions dans le journal Folha de S. Paulo

Dans cet article, on a cherché à comprendre les connaissances véhiculées par le journal Folha de $S$. Paulo au sujet du référendum sur les armes à feu pendant l'année 2005. On a effectué des recherches sur le site du journal - version imprimée du site et version en ligne - par l'intermédiaire de descripteurs: référendum ; arme à feu ; munitions, dont on a trouvé 170 articles. Le matériel a 
été analysé par le logiciel Alceste, qui effectue l'analyse des données textuelles via le classement hiérarchique décroissant. Les résultats indiquent une discussion du référendum organisée en deux axes de sens, de l'ordre de la Sécurité privée vs Securité publique, dans laquelle des thèmes tels que le contrôle des armes et des munitions illégales sont traités en second plan, montrant ainsi la nécessité d'approfondir cette discussion.

Mots-clés: armes à feu; munitions; presse; référendum

Artigo submetido à publicação em novembro de 2015.

Versão final aprovada em julho de 2016. 